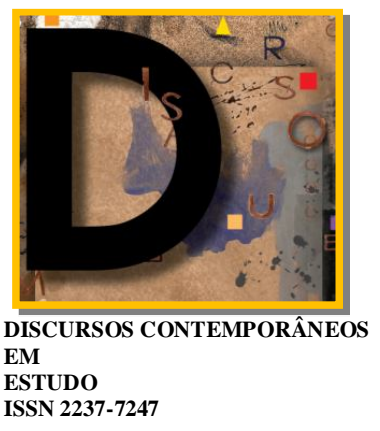

\title{
FAIRCLOUGH, N. ANALYSING DISCOURSE: TEXTUAL ANALYSIS FOR SOCIAL RESEARCH. LONDRES: ROUTLEDGE, 2003, $270 \mathrm{P}$.
}

Claudia Gomes Paiva $(\mathrm{UnB})^{1}$

RESENHA/REVIEW

\begin{abstract}
Palavras-chave: Análise de Discurso Crítica (ADC). Pesquisa social. Discurso. Análise textual. Linguagem.
\end{abstract}

Keywords: Critical Discourse Analysis (CDA). Social research. Discourse. Textual analysis; Language

Com Analysing discourse: textual analysis for social research, Norman Fairclough intenta transpor dois obstáculos no que se tem produzido com base no entremeio das análises linguística e social. $\mathrm{O}$ primeiro diz respeito à constrangida abordagem de temas que interessam aos pesquisadores sociais; o segundo, à dificuldade de uma frutífera sistematização das análises da linguagem em direção à pesquisa social.

De acordo com o autor, não se trata de um livro meramente dedicado à análise de textos porque tudo o que ali é discutido insere-se no amplo quadro das transformações sociais contemporâneas. A Análise de Discurso Crítica (ADC) vai, pois, figurar como importante fonte para as ciências sociais em um projeto mais amplo: partindo do paradigma de análise da linguagem no novo capitalismo - efetivada no livro -, os estudos podem, e devem, ser construídos em qualquer campo, não somente com a efetivação de descrições, mas, sobretudo, objetivando efeitos sociais transformadores. Nesse sentido, o autor remete (p. 3, Introdução) ao manifesto incluído no capítulo de conclusão, cuja leitura antecipada muito contribui para a compreensão da obra. Restando claro que a recepção do texto e sua interpretação constituem etapas relevantes no processo da construção do sentido, é sobre a etapa de produção textual que Fairclough estará debruçado.

O livro está dividido em quatro partes, em que a primeira contextualiza e correlaciona as análises social, discursiva e textual, bases para as partes seguintes, que analisarão os três

\footnotetext{
${ }^{1}$ Doutora em Linguística pela Universidade de Brasília (UnB); consultora legislativa na área de Redação e Discurso Parlamentar. E-mail: claudia.paiva@camara.gov.br.
} 
significados propostos pelo autor: a segunda dedica-se ao significado acional; a terceira, ao representacional; e a quarta, ao identificacional.

Completando a edição, são incluídos dois glossários (um dos termos-chave da análise textual e da pesquisa social empregados, e outro dos principais teóricos citados) e um apêndice com a íntegra dos textos analisados ao longo dos capítulos.

A Parte I (Análise social, análise do discurso e análise textual), subdividida nos capítulos 2 e 3, explicita a relação dialética existente entre as análises constantes do seu título, mais que etapas, processos imbricados altamente relevantes na descrição e na interpretação da configuração da sociedade em sentido amplo. O Capítulo 2 aprofunda-se aí, de modo que os textos são tidos como parte dos eventos sociais, que, por sua vez, conformam-se às práticas sociais em que estão inseridos. É neste capítulo que Fairclough registra a reelaboração de seu próprio modelo teórico (proposto em 1992, em Discurso e mudança social - traduzido para o português em 2001), ao articular as funções ali propostas (relacional, ideacional e identitária) aos conceitos de gênero, discurso e estilo, o que resulta em três tipos de significado: acional, representacional e identificacional.

O significado acional tem no gênero o meio de estudo do texto na interação social, comportando categorias de análise como a intertextualidade e a pressuposição. O significado representacional volta-se para o discurso como modo de representação de aspectos do mundo, o que faculta a articulação de mais de um discurso em um mesmo texto (a interdiscursividade), ao lado da categoria "significado da palavra". No terceiro e último significado - identificacional -, o estilo sobressai em sua relação com os atores sociais presentes no texto. As categorias aqui são, principalmente, avaliação e modalidade. Quanto à função textual, tão cara a Halliday, Fairclough opta por sua incorporação ao significado acional, restando incólume a multifuncionalidade desde longe apregoada entre as funções, agora, entre os significados.

No Capítulo 3, por meio das categorias de intertextualidade e de suposição, o foco são as relações entre os textos, de modo a especificar o quanto de um texto - ou de mais de um - é percebido no texto em análise. A intertextualidade é tomada pelo autor no sentido mais amplo, indo do discurso direto ao indireto, e permite acessar as muitas vozes presentes no texto, a organização delas. Semelhantemente, na análise há de se investigar quais outras vozes são deixadas fora do texto e por quais razões. Além do aspecto da seletividade, a intertextualidade pressupõe recontextualização na medida em que a transferência de vozes para outros contextos obrigará que se façam escolhas para o enquadramento, o que resulta inevitavelmente na hierarquização dessas vozes. O conceito de suposição aparece neste capítulo, completando o circuito de "relações externas" aos textos: "o que é 'dito' em um texto ampara-se no pano de fundo do que não é 'dito', mas tomado como dado” (p. 40, tradução minha). As suposições, 
principalmente classificadas em existenciais, proposicionais e valorativas, apontam para a pragmática e sua consideração da linguagem em uso.

A conexão com a pesquisa social se faz com a exploração de três principais temas. $\mathrm{O}$ nada inocente tratamento da diferença social - que se vem acentuando com as transformações sociais - emerge dos textos de modo inegável, apontando para os meandros de sua constituição. A questão da hegemonia, do que é universal e do que é particular - e a substituição de um pelo outro - também é prolífica nas categorias linguísticas presentes nos textos. Por último, a ideologia carreada aos textos pelas suposições não deixa dúvidas quanto à pertinência da análise textual.

A Parte II (Gêneros e ação), que compreende os capítulos 4, 5 e 6, trata do significado acional, descrito mediante o conceito de gênero, categoria de fluxo altamente variável em estabilidade e homogeneidade, o que prejudica a adoção de uma classificação rígida.

No Capítulo 4, Fairclough aclara a terminologia por ele adotada ao explicitar, em conformidade com o grau de abstração, que pré-gêneros estão no topo; gêneros fragmentados (ou “desencaixados"), na categoria intermediária; e gêneros situados, na base, como gêneros específicos de práticas sociais particulares. Quanto à franca possibilidade de hibridização de gêneros nos textos, há duas formas principais: os formatos (junção de diferentes textos de diferentes gêneros) e a relação hierarquizada entre eles (gênero principal e subgêneros).

Adotando um enfoque restrito, a análise de gêneros individuais em um texto particular, Fairclough detalha os gêneros, ou melhor, pré-gêneros diálogo, argumento e narrativa, mediante três categorias: atividade (“o que as pessoas estão fazendo?"), relações sociais (“quais são as relações sociais entre elas?") e tecnologia de comunicação ("de qual tecnologia (se alguma) elas dependem?”) (tradução nossa, p. 70). Toda essa análise genérica conecta-se à pesquisa social nos temas de desencaixe de material social de práticas sociais particulares, objetivos sociais dos gêneros, "conversacionalização" do discurso público, relação entre mudança social e tecnológica e discussão da ideologia.

O Capítulo 5, ao tratar das relações de significado entre períodos e orações, traz as relações semânticas e gramaticais, que oferecem suporte a categorias da pesquisa social como legitimação, hegemonia, equivalência e diferença. Enquanto as relações semânticas dizem respeito a significados causais, condicionais, temporais, aditivos, elaborativos e contrastivos/concessivos - sem prejuízo daquelas em nível mais elevado, como as relações problema-solução e objetivo-cumprimento -, as relações gramaticais referem-se principalmente às relações de coordenação e de subordinação. E, uma vez que o emprego dessas relações encontradas em um texto depende da sua categoria genérica, as análises propostas por Fairclough vão ao encontro do explicitado no capítulo precedente. 
Semelhantemente, o Capítulo 6 vai olhar para a relação entre as orações e especificar, na análise textual, a classificação delas de acordo com o tipo de troca (troca de conhecimento, de atividade), funções da fala (declarações, perguntas, pedidos, ofertas) e modo gramatical (declarativo, interrogativo, imperativo) e, na pesquisa social, conforme a ação comunicativa e estratégica, cultura promocional, políticas públicas, entrevistas de pesquisa.

A Parte III (Discursos e representações), que compreende os capítulos 7 e 8, atém-se ao significado representacional, em que o mundo material e as práticas sociais aí inseridas são representados e, mais importante, de diferentes perspectivas.

No Capítulo 7, Fairclough define discursos como modos de representar aspectos do mundo, não somente materiais, mas também mentais, sentimentos e crenças, considerando que a pluralidade de aspectos desemboca na pluralidade de discursos. Os vários e diferenciados níveis de abstração, embora, de um lado, revelem certo grau de repetição em termos de estabilidade, de outro, compreendem uma variabilidade discursiva interna. A aparente contradição se desfaz ao lembrarmos a relação dialética de que o discurso e os demais elementos da vida social desfrutam. Eis a porta aberta para a interdiscursividade, a análise da articulação de diferentes discursos nos textos, discursos esses que aparecem em relações dialógicas ou polêmicas. Por outro lado, os traços linguísticos inerentes aos modos de representação, portanto, presentes nos discursos, são os de vocabulário - mais óbvios - como também as relações semânticas construídas entre as palavras e não encontradas nos dicionários (estruturas de hiponímia, sinonímia e antonímia), além das colocações (collocations), que vêm a ser os padrões de co-ocorrência das palavras nos textos, e das suposições aqui já discutidas.

A metáfora surge como outro importante mecanismo de diferenciação dos discursos. Fairclough descreve uma distinção entre a metáfora lexical - no sentido mais usual - e a metáfora gramatical, que representa processos como entidades por meio das nominalizações.

O Capítulo 8 traz, representados nas orações, aspectos do mundo social em termos da representação de eventos sociais. Desse modo, as orações contêm três tipos principais de elementos: processos (verbos), participantes (sujeitos, objetos, objetos indiretos de verbos) e circunstâncias (elementos adverbiais). Fairclough assim esquematiza a representação de acordo com os tipos de processos (material, verbal, mental, duas categorias de relacional e existencial): participantes (ator, afetado, experienciador, portador, símbolo, valor, existente) e as circunstâncias (tempo, lugar, finalidade, razão, modo, meio).

Quanto aos eventos sociais, eles abrangem as formas de atividade, pessoas, formas institucionais, objetos, meios, tempo e espaço, linguagem e outros tipos de semiose. Incluem também diferentes níveis de abstração e generalização, indo das representações de eventos sociais específicos (maior concretude), passando pela abstração de séries e conjuntos de eventos 
sociais, para chegar ao mais abstrato, o nível das práticas sociais ou estruturas sociais. $\mathrm{Na}$ medida em que a representação dos eventos obriga a adoção de esquemas de classificação, retoma-se o conceito de recontextualização: a incorporação de um evento social no contexto de outro evento segundo os princípios de presença, de abstração, de disposição e de adição.

Especialmente relevantes no que diz respeito à representação da agência - com repercussão no significado social -, as escolhas implicadas na representação dos atores sociais (normalmente participantes, mas nem sempre) esteia-se nas seguintes variáveis: inclusão/exclusão, pronome/nome, papel gramatical, ator social ativo/passivo, pessoal/impessoal, nomeação/classificação, específico/genérico.

Na representação das circunstâncias, especialmente tempo e espaço, Fairclough defende, na análise textual, a operacionalização do pensamento do geógrafo inglês David Harvey, para quem espaço e tempo são construtos sociais, portanto, diferentes em sociedades diversas e, consequentemente, interligados a relações sociais e identitárias particulares.

$\mathrm{Na}$ Parte IV (Estilos e identidades), capítulos 9 e 10, chega-se ao terceiro e último tipo de significado proposto por Fairclough. Conforme o Capítulo 9, o significado identificacional é captado pela categoria estilo, por meio do qual as pessoas se identificam e são identificadas por outros, ressalvando-se a importância da distinção entre aspectos identitários pessoais (personalidade) e sociais (identidade social), que refletem na elaboração do conceito de agência, considerada a relação dialética em que se inserem e que determina os níveis de abstração correspondentes (mais abstrato - papéis estáveis ao longo da vida social; menos abstrato identidades pessoais investem-se de modos distintivos). Os principais traços linguísticos associados a estilos são os fonológicos, o vocabulário e a metáfora. E a inter-relação linguagemlinguagem corporal é relevante para o estilo, revitalizando a conformação dialética entre aspectos discursivos e não discursivos do mundo, especialmente se considerada a crescente utilização da multissemiótica nos eventos sociais e, consequentemente, nos discursos.

Também compondo o significado identificacional, o Capítulo 10 analisa as categorias textuais de modalidade e avaliação, ambas relevantes para a tessitura das identidades sociais e para a pesquisa social no que diz respeito aos temas sobre como as identidades são estabelecidas no texto, sua heterogeneidade, a construção da imagem, de novo a relação personalidade e identificação social, cidadania e esfera pública.

A modalidade diz respeito à relação entre o produtor do texto e as representações aí construídas. Verdade e necessidade vão aparecer em gradação conforme a visão eleita para representar o mundo, o que torna clara a conexão entre modalidade - tipificada em epistêmica e deôntica - e tessitura da identidade social. Há marcadores típicos como verbos e advérbios 
modais, mas também se pode recorrer à modalidade por meios não explícitos, escolhas que estarão sempre condicionadas a limites de natureza social.

A avaliação, subdividida em quatro tipos (declarações avaliativas, declarações com modalidade deôntica, declarações com verbos de processo mental afetivo, suposições de valor), grosso modo, implica percepções do que é desejável ou não, do que é bom ou mau, em uma gradação de intensidade. Importante frisar que, nos casos menos explícitos de avaliação, aumenta a força da relação com discursos particulares para a categorização como estrutura avaliativa. Configurada de modo explícito ou não nos textos, a avaliação revela-se prolífica na investigação de tópicos sociais como, por exemplo, a comparação entre os estilos das identidades (mistas, heterogêneas, contraditórias), a estetização das identidades públicas e a tensão entre identidade social e personalidade.

O capítulo de conclusão de Norman Fairclough resume as diversas categorias analíticas textuais abordadas, conectando-as aos tópicos da pesquisa social também explicitados no livro. Nesse contexto, a ADC, mais que análise textual, é uma forma de pesquisa social crítica a se encaixar em um projeto maior das ciências sociais e, dessa perspectiva, permite, ou melhor, estimula a transdisciplinaridade.

Consideradas as radicais mudanças por que passa o mundo contemporâneo, e como os discursos figuram nesse processo, Fairclough chama a atenção para o fato de que se deve focar língua e discurso da perspectiva da transformação da vida social, transformação essa dialeticamente relacionada à linguagem. Por isso, não basta supor o papel do discurso nas práticas sociais; impõe-se efetuar a análise que a ADC tem-se esforçado em embasar. Essa, a suma dos pontos mais relevantes tratados por Fairclough na reformulação teórica elaborada. Sempre conectado ao trabalho de Halliday na Linguística Sistêmica Funcional (LSF), reitera que a análise discursiva é apenas um dos métodos que podem incrementar a pesquisa crítica nas ciências sociais e que, além disso, suas categorias são provisórias porque em constante aperfeiçoamento.

Voltando-nos para Discurso e mudança social (1992/2001), a concepção tridimensional do discurso (prática social, prática discursiva e texto) ali analisada subjaz à tripartite caracterização das análises propostas em 2003 - embora aquela terminologia não se tenha repetido - com vistas à pesquisa social, quais sejam a análise social, a análise do discurso e a análise textual. Da mesma sorte, a primeira obra trazia o embrião que resultaria nos significados posteriormente detalhados. Naquela ocasião, gênero, discurso e estilo foram tratados como elementos que compunham as ordens do discurso, portanto, abertos à articulação, embora longe de constituírem uma demarcação analítica rígida. Fairclough os justificava sob dois argumentos: 
o emprego dos conceitos por cientistas sociais e o reforço oferecido à validade do método da análise do discurso na pesquisa social.

Em 2003, a conexão entre uma e outra aparece explicitamente marcada na medida em que se recomendam os itens tanto para análise textual quanto para pesquisa social, no contexto da inter-relação dos significados acional, representacional e identificacional. Evidentemente, a fragmentação conceitual com que o livro nos confronta atende a princípios didáticos, facilitadores, portanto, da compreensão dos componentes destacados. Da mesma maneira, o reconhecimento da fértil relação dialética entre linguagem e demais elementos da vida social revigora a pertinência das pesquisas sociais que ousam lançar mão do arcabouço teórico que esteia a análise linguística.

Os capítulos (do 2 ao 10) são encerrados com pequenos resumos que precedem a leitura de cada capítulo por eles, o que certamente preparará os leitores para o detalhamento que consta da obra, procedimento congênere ao sugerido pelo próprio Fairclough quanto à leitura do seu "manifesto".

Por fim, no que se refere aos exemplos que dão suporte às análises textuais, teria sido de grande valia a inclusão de um encarte destacável que reproduzisse todos eles, facilitando o cotejo com a teoria nos pontos em que os dados são chamados ao comento. Norman Fairclough segue aprimorando o quadro teórico da Análise de Discurso Crítica, propiciando estudos cada vez mais socialmente contextualizados. A obra de 2003 segue esse traçado, brindando-nos com um reoxigenado estudo da teoria social do discurso.

\section{Referências}

FAIRCLOUGH, N. Discourse and social change. Cambridge: Polity Press, 1992.

. Discurso e mudança social. Brasília: UnB, 2001.

HALliDAY, M. A. K.; HASAN, R. Language, Context and Text: Aspects of language in a social-semiotic perspective. Oxford:Oxford University Press, 1985. 
